\title{
Tricuspid atresia in adolescents and adults: current state and late complications
}

\author{
CAROLE A WARNES, JANE SOMERVILLE \\ From the Paediatric and Adolescent Unit, National Heart Hospital, London
}

SUMMARY Twenty nine patients aged 15-35 years (mean 23) with tricuspid atresia and normally related great arteries were studied; 20 are alive. Ten patients who had had a Fontan operation (group 1) were compared with 10 patients with palliative shunts (9) or no surgery (1) (group 2). Patients were graded according to their ability to lead a normal life (ability index). Patients in group 1 tended to have a better ability index, a greater exercise capacity, and fewer social and extracardiac problems than those in group 2. The mean left ventricular ejection fraction measured by radionuclide angiography was the same in both groups. Arrhythmias were equally common in both groups; they appear to be age related and they occur independently of left ventricular function.

Increasing numbers of patients with tricuspid atresia are surviving to adolescence and adult life as a result of early palliative and reparative operations. Information about the late results is scarce and little is known of the medical and social problems that these patients encounter in adulthood. We have reviewed all patients with tricuspid atresia and normally related great arteries who attended the National Heart Hospital since 1965 and who survived beyond their fourteenth birthday. Procedures used for the management of complex heart disease are constantly changing and the survival of many of these adults is the result of pioneering efforts. We have examined the ability of such patients to lead a normal life in the long term.

\section{Patients and methods}

In 1985-86 we reviewed all patients with tricuspid atresia and normally related great arteries attending the National Heart Hospital since 1965 who survived to their fourteenth birthday. Patients were referred with complex problems from many centres and they represent a highly selected group. In all of them the diagnosis was confirmed by invasive

Requests for reprints to Dr Jane Somerville, Paediatric and Adolescent Unit, National Heart Hospital, Westmoreland Street, London W1M 8BA.

Accepted for publication 22 August 1986 investigation. In four cases a necropsy was performed. Twenty of the 29 patients ( $16 \mathrm{men}$ ) aged 16-35 years (mean 23) are alive and all except one attended for review. The records of the nine patients who died were scrutinised and the cause of death was determined.

Nineteen of the 20 survivors seen in $1985-86$ had clinical examination, chest $x$ ray, electrocardiogram, 24-48 hour ambulatory monitoring, symptom limited exercise test by the modified Bruce protocol, and cross sectional echocardiography. Left ventricular function was also assessed with equilibrium electrocardiogram gated radionuclide angiography.

We assessed the patient's ability to lead a normal life according to the index shown in fig 1 . We paid particular attention to difficulties with employment,

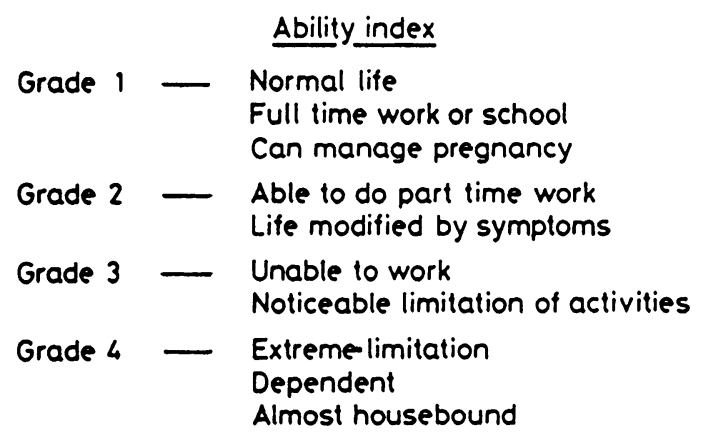

Fig 1 Ability index classification. 
Table 1 Summary of clinical data on 15 patients with tricuspid atresia and a Fontan operation

\begin{tabular}{|c|c|c|c|c|c|c|c|c|}
\hline Case No & $\begin{array}{l}\text { Age reached } \\
(y r)\end{array}$ & Sex & $\begin{array}{l}\text { Operations before Fonta } \\
\text { operation } \\
\text { and Age (yr) }\end{array}$ & & $\begin{array}{l}\text { Age at } \\
\text { Fontan (yr) }\end{array}$ & $\begin{array}{l}\text { Ability } \\
\text { index }\end{array}$ & Rhythm problems & $\operatorname{LVEF}(\%)$ \\
\hline \multicolumn{9}{|l|}{ Alive: } \\
\hline$\frac{1}{2}$ & $\begin{array}{l}35 \\
26\end{array}$ & $\begin{array}{l}\mathbf{F} \\
\mathbf{M}\end{array}$ & $\begin{array}{l}\text { None } \\
\text { Blalock-Taussig shunt } \\
\text { Waterston shunt }\end{array}$ & $\begin{array}{l}4 \\
8\end{array}$ & $\begin{array}{l}22 \\
12\end{array}$ & $\begin{array}{l}2 \\
2\end{array}$ & $\begin{array}{l}\text { None } \\
A-V \text { dissociation }\end{array}$ & $\begin{array}{l}37 \\
42\end{array}$ \\
\hline $\begin{array}{l}3 \\
4\end{array}$ & $\begin{array}{l}24 \\
23\end{array}$ & $\begin{array}{l}M \\
M\end{array}$ & $\begin{array}{l}\text { Blalock-Taussig shunt } \\
\text { Glenn anastomosis } \\
\text { Blalock-Taussig shunt } \\
\text { Blalock-Taussig shunt }\end{array}$ & $\begin{array}{l}4 \\
2 / 12 \\
12 \\
18\end{array}$ & $\begin{array}{l}15 \\
21\end{array}$ & $\begin{array}{l}1 \\
2\end{array}$ & $\begin{array}{l}\text { None } \\
\text { None }\end{array}$ & $\begin{array}{l}30 \\
51\end{array}$ \\
\hline $\begin{array}{l}5 \\
6\end{array}$ & $\begin{array}{l}23 \\
21\end{array}$ & $\mathbf{F}$ & $\begin{array}{l}\text { Glenn anastomosis } \\
\text { Glenn anastomosis } \\
\text { Blalock-Taussig shunt }\end{array}$ & $\begin{array}{l}2 / 12 \\
8 / 12 \\
8\end{array}$ & $\begin{array}{l}11 \\
12\end{array}$ & $\begin{array}{l}3 \\
2\end{array}$ & $\begin{array}{l}\text { Atrial tachycardia } \\
\text { Ventricular tachycardia }\end{array}$ & $\begin{array}{l}56 \\
51\end{array}$ \\
\hline 7 & 20 & $\mathbf{M}$ & $\begin{array}{l}\text { Glenn anastomosis } \\
\text { Blalock-Taussig shunt }\end{array}$ & $\begin{array}{l}4 / 12 \\
5\end{array}$ & $\begin{array}{r}9 \\
17\end{array}$ & 2 & Multiple APCs & 35 \\
\hline 8 & 20 & $\mathbf{M}$ & $\begin{array}{l}\text { Blalock-Taussig shunt } \\
\text { Waterston shunt }\end{array}$ & $\begin{array}{l}1 \\
5\end{array}$ & 16 & 2 & None & 70 \\
\hline 9 & 18 & $\mathbf{M}$ & $\begin{array}{l}\text { Waterston shunt and } \\
\text { Blalock-Hanlon }\end{array}$ & $9 / 12$ & 16 & 2 & None & 39 \\
\hline \multirow{2}{*}{$\begin{array}{c}10 \\
\text { Dead: } \\
11\end{array}$} & 16 & $\mathbf{F}$ & None & & 11 & \multirow{2}{*}{\multicolumn{2}{|c|}{$\begin{array}{l}2 \\
\text { Cause of death } \\
\text { Sepsis }\end{array}$}} & 48 \\
\hline & 25 & $\mathbf{M}$ & $\begin{array}{l}\text { Blalock-Taussig shunt } \\
\text { Waterston shunt }\end{array}$ & $\begin{array}{r}4 \\
21\end{array}$ & 25 & & & \\
\hline 12 & 22 & $\mathbf{F}$ & $\begin{array}{l}\text { Blalock-Taussig shunt } \\
\text { Glenn anastomosis } \\
\text { Potts shunt }\end{array}$ & $\begin{array}{r}1 \\
10 \\
17\end{array}$ & 22 & \multicolumn{3}{|c|}{$\begin{array}{l}\text { Poor left ventricular function, raised pulmonary } \\
\text { artery pressure }\end{array}$} \\
\hline 13 & 22 & $\mathbf{F}$ & $\begin{array}{l}\text { Blalock-Taussig shunt } \\
\text { Waterston shunt }\end{array}$ & $\begin{array}{r}5 \\
14\end{array}$ & 22 & \multicolumn{3}{|c|}{ Sudden } \\
\hline 14 & 17 & $\mathbf{F}$ & $\begin{array}{l}\text { Blalock-Taussig shunt } \\
\text { Blalock-Taussig shunt }\end{array}$ & $\begin{array}{l}2 / 12 \\
2\end{array}$ & 17 & \multicolumn{3}{|c|}{ Atrial arrhythmias, left ventricular failure } \\
\hline 15 & 15 & $\mathbf{F}$ & Blalock-Taussig shunt & $7 / 12$ & 15 & \multicolumn{3}{|c|}{ Postoperative hypoxia } \\
\hline
\end{tabular}

APCs, atrial premature complexes; A-V, atrioventricular; LVEF, left ventricular ejection fraction.

education, training, contraception, and marriage, and whether the patient had been successful in obtaining a driving licence and life insurance.

We divided the patients into two groups; group 1 comprised 15 patients with Fontan's operation, and group 2, 14 patients with previous shunts or Glenn anastomoses including one woman aged 32 years who had not had operation. Tables 1 and 2 summarise the clinical data.

\section{Results}

\section{GROUP I: PATIENTS WITH A FONTAN OPERATION}

Fifteen patients had had a Fontan operation at age 9-25 years (mean 16) (table 1). All except two (cases 1 and 10) had had one or more previous shunts or a Glenn anastomosis. Three patients (cases 9, 14, and 15) had had an arteriopulmonary shunt and four (cases 4, 5, 6, and 7) had had a Glenn anastomosis in infancy ( $<1$ year). Two patients (cases 4 and 12) had had three previous shunts. Two patients (cases 1 and 7) have small residual atrial septal defects and one patient (case 8) has a residual ventricular septal defect.

\section{Mortality}

Five patients died one day to one year after the Fon- $\tan$ operation. Three died in the early postoperative period. A fourth (case 11) died six months later of uncontrolled sepsis after a reoperation for an open atrial septal defect. A woman of 22 (case 13) died unexpectedly after a bout of vomiting a year after an apparently successful Fontan operation (ability index 2). Postoperative angiography at six months had shown that the pulmonary vascular resistance was slightly increased as a result of the previous Waterston shunt. Necropsy showed that the unvalved conduit between right atrium and right ventricle was open, but it was lined with intimal peel.

\section{Reoperation}

Two of the 15 patients required late reoperation 10 years after the original Fontan procedure because of obstruction of the Dacron conduit connecting the right atrium to the pulmonary arteries. The conduit was replaced with an aortic valve homograft. Both patients had a functioning Glenn anastomosis which masked the conduit obstruction until they presented with presyncope. In both of them left ventricular function has deteriorated since reoperation. One (case 7) has angina that is probably associated with large acquired mediastinal coronary-bronchial collaterals causing a steal phenomenon (fig 2). The other (case 5) has congestion and a low cardiac out- 
Table 2 Summary of clinical data on 14 patients with tricuspid atresia who had palliative shunts or no surgery

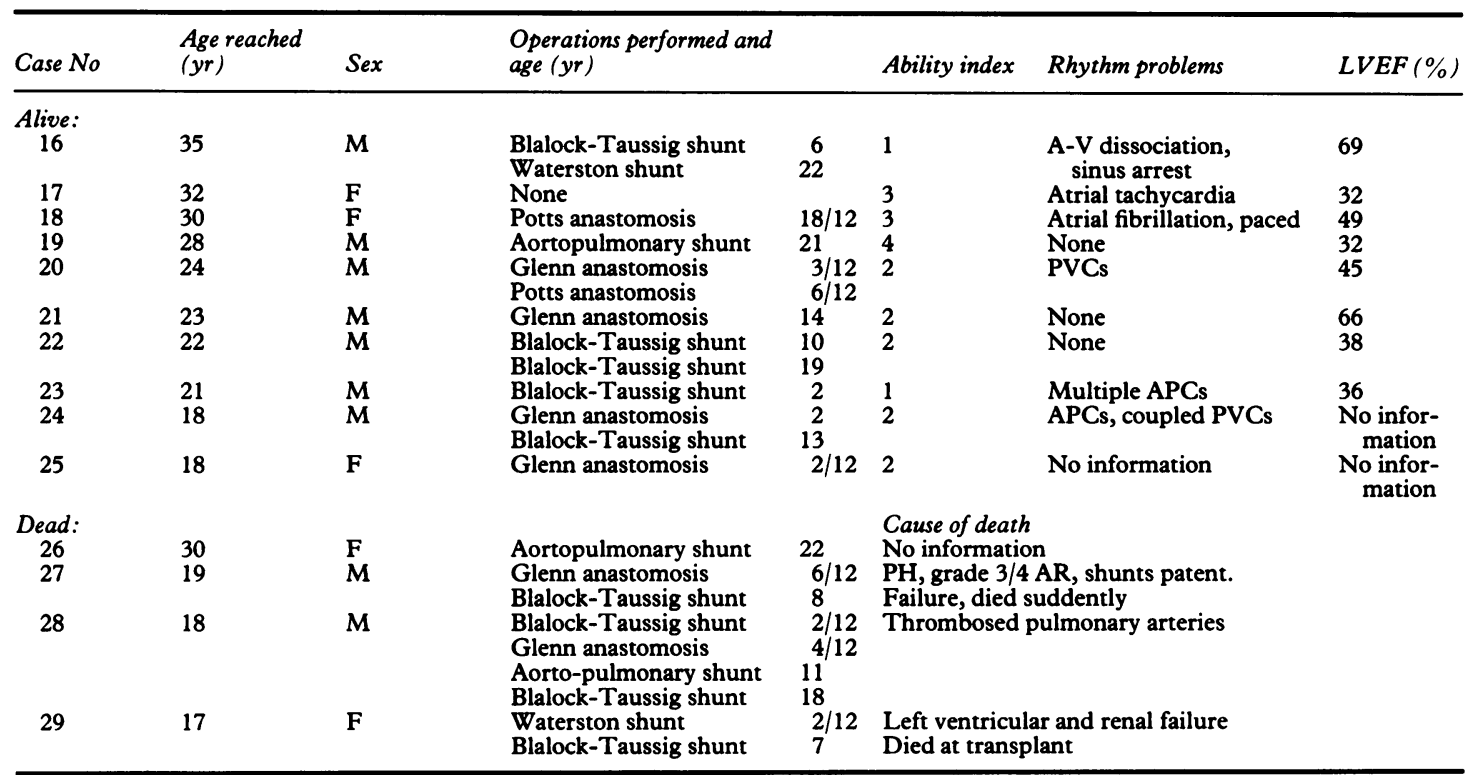

APCs, atrial premature complexes; AR, aortic regurgitation; A-V, atrioventricular; LVEF, left ventricular ejection fraction; PH, pulmonary hypertension; PVCs, premature ventricular complexes.

put (ability index 3 ) related to a residual ventricular septal defect and a right ventricular-pulmonary artery connection; pulmonary artery pressure is raised ( $23 \mathrm{~mm} \mathrm{Hg}$ systolic). It is hoped that ligation of the proximal pulmonary artery will reduce the pulmonary artery pressure.

\section{Arrhythmias}

Arrhythmias developed in four patients; in all of them they started after 20 years of age. Three have symptoms (cases 2, 5, and 6). In case 2 recurrent supraventricular tachycardia is controlled by amiodarone; this patient leads a normal life despite the intermittent atrioventricular dissociation that is shown by ambulatory monitoring. One patient (case 5) has non-sustained multifocal atrial tachycardia if she forgets to take a diuretic. In patient 6 nonsustained ventricular tachycardia developed at 20 years, eight years after her Fontan operation; this has responded to phenytoin. One other patient (case 7) has asymptomatic non-sustained multifocal atrial tachycardia. There was no apparent correlation between left ventricular dysfunction and the presence or onset of arrhythmias (fig 3).

The other six surviving patients, aged 16-35 years, are in sinus rhythm.

Functional status of survivors

Nine of the 10 survivors with Fontan procedures aged 16-35 years (mean $2 \hat{3}$ ) remain well and acyanotic. One (case 1) has a residual atrial septal defect and cyanosis. Figure 4 shows the postoperative changes in ability index of each patient. Nine patients are currently leading nearly normal lives. Figure 5 shows their exercise capacity and ability index. One patient (case 1) was limited to stage I because of obesity and pain from a previous deep vein thrombosis that occurred after the Fontan operation. Four patients were limited to stage II.

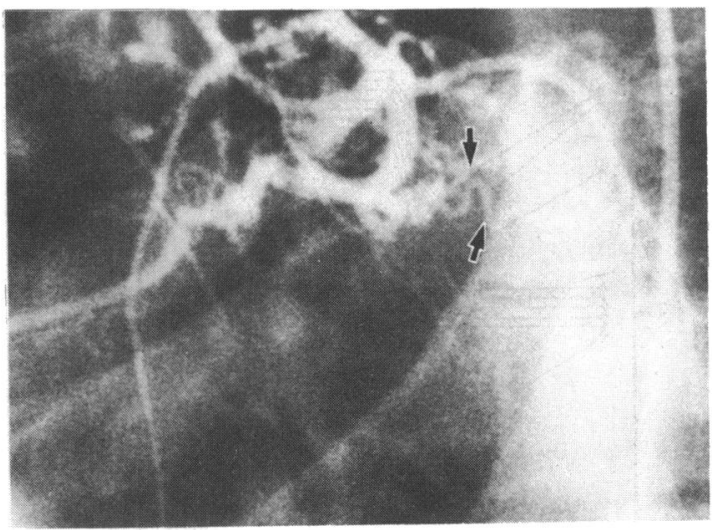

Fig 2 Injection into the left coronary system in case 7. There are multiple coronary collaterals (arrows) arising from the left circumflex coronary artery. 
Fontan procedure Shunts or no operation

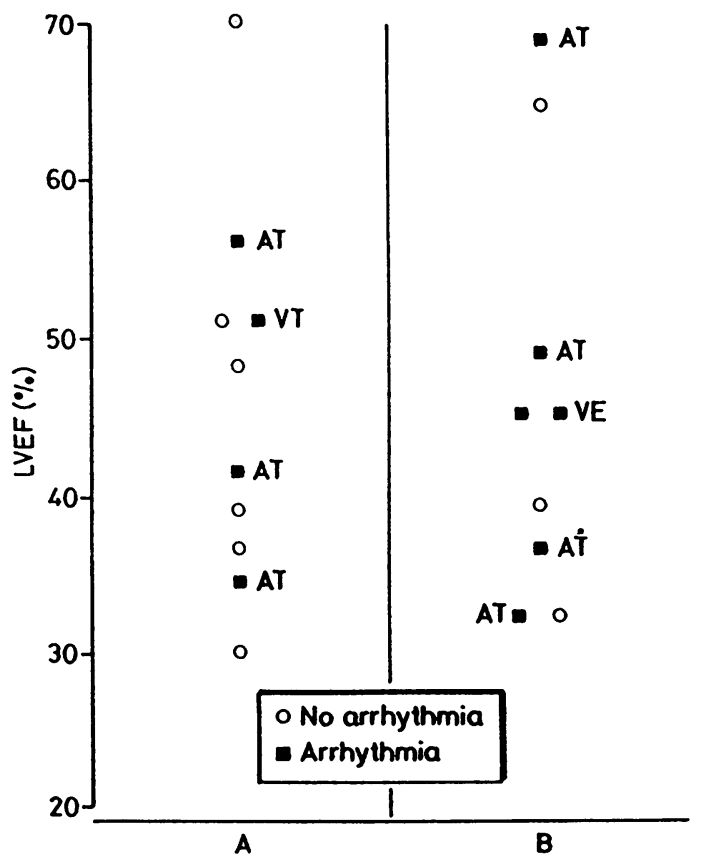

Fig 3 Left ventricular ejection fraction ( $L V E F$ ) measured by radionuclide angiography of 10 patients with a Fontan operation and nine patients with palliative shunts or no surgery. There is no correlation between the presence of arrhythmias and LVEF. AT, atrial tachycardia; VE, frequent ventricular ectopic impulses; $V T$, ventricular tachycardia.
There was no correlation between exercise capacity and ability index.

Measured left ventricular ejection fraction (table 1) ranged from $30 \%$ to $70 \%$ (mean 46 ) and did not correlate with exercise capacity (fig 6) or ability indices (fig 7). Patients in whom arteriopulmonary shunts had been inserted during infancy (cases 8 and 9) did not have worse left ventricular function than those who had shunts later. The age at which the Fontan operation was performed did not seem to influence left ventricular function.

\section{Quality of life}

School and employment-Five of the 10 survivors had been so disabled in childhood that they had attended schools for the handicapped. Eight now work full time or are at college or school. One (case 7) had a problem with drugs and alcohol during adolescence but is now employed full time. Two patients cannot find employment; one of them (case 5) with a grade 3 ability index is awaiting further reoperation.

Marriage-Three patients (two men) have married; a woman (case 1) has no children, has had a nervous breakdown and is now divorced. The two men (cases 2 and 7) are married and have five normal children. Two unmarried women (cases 5 and 6) take the combined oral contraceptive pill without complication.

Driving and life insurance-All six patients who applied for driving licences have obtained them subject to review. Only one patient (case 2 ) has obtained

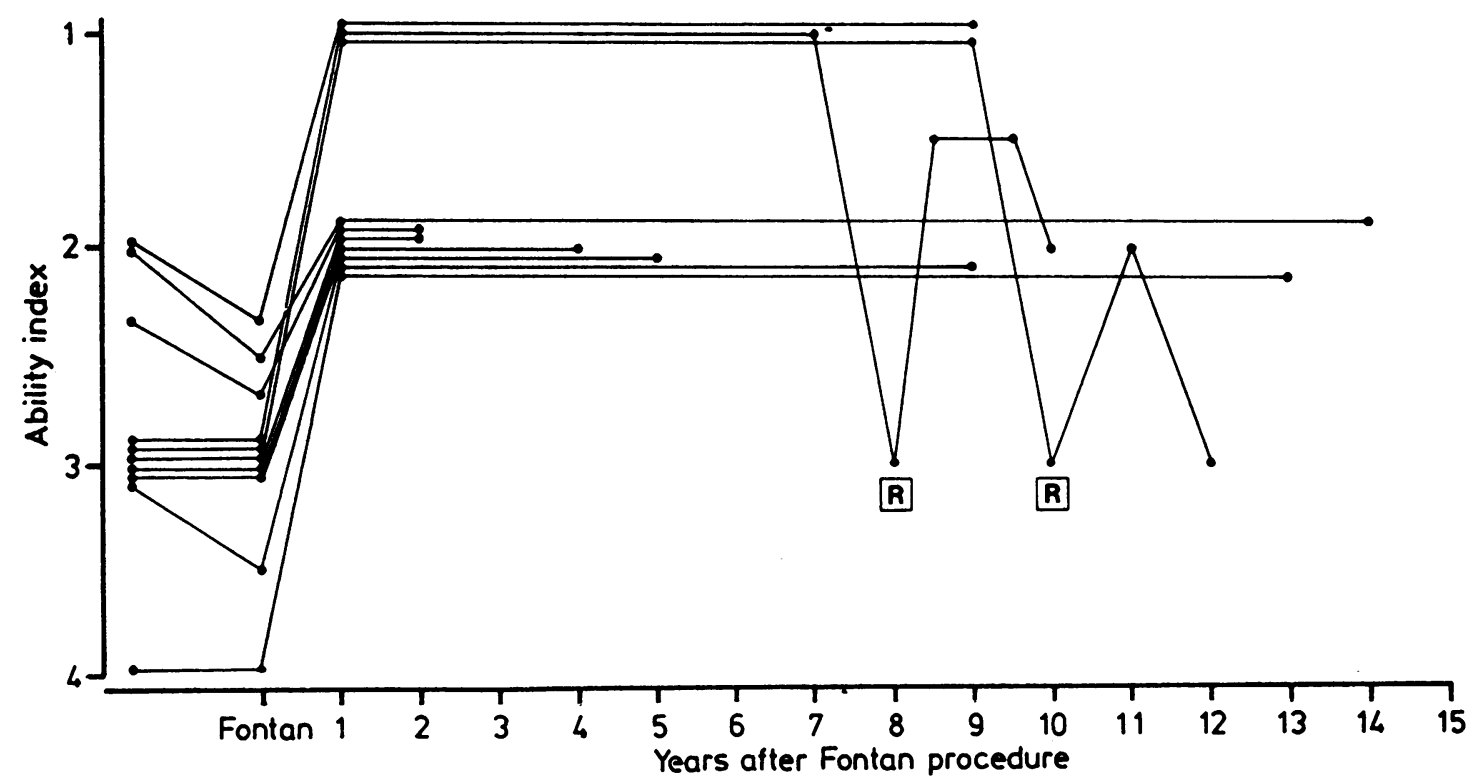

Fig 4 Change in ability index of 10 patients before and after the Fontan operation. $R$; reoperation. 
Fontan procedure Shunts or no operation

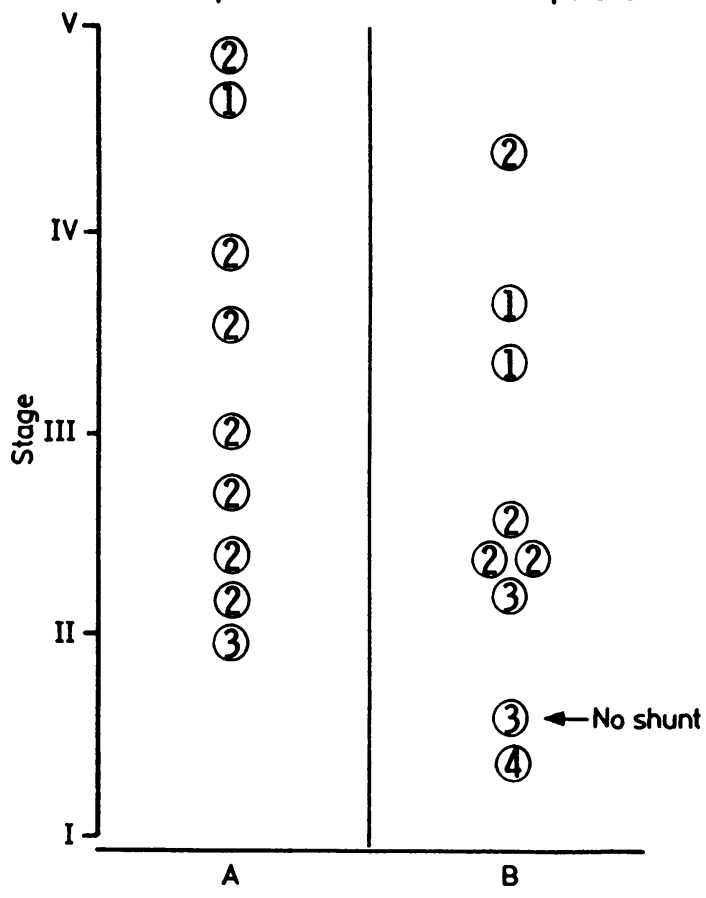

Fig 5 Exercise capacity according to the modified Bruce protocol of nine patients with a Fontan operation and nine patients with palliative shunts or no operation. Ability index of each patient is shown.

life insurance (with substantial loading); the others did not try for life insurance.

Medication-Three patients (cases 1, 3, and 7) take no medication; the seven others are taking diuretics or antiarrhythmic treatment or both. There are no extracardiac problems.

\section{GROUP 2: PATIENTS WITH EXTRACARDIAC PALLIATIVE PROCEDURES OR NO PREVIOUS OPERATION}

Fourteen patients aged 17-35 years (table 2) had either arteriopulmonary shunts (7) or a Glenn anastomosis (2), or both (4) and one (case 17) reached the age of 32 years without surgery but there had been a deterioration in ability index to 3 in the past three years. When she was 24 and the oxygen saturation was $81 \%$ and the pulmonary artery pressure was $18 / 15 \mathrm{~mm} \mathrm{Hg}$ she was regarded as suitable for a Fontan operation. She refused operation until the age of $\mathbf{3 2}$ years when arterial oxygen saturation was $70 \%$. At reinvestigation the pulmonary artery pressure could not be measured. At operation for an intended Fontan procedure the pulmonary artery pressure was $60 \mathrm{~mm} \mathrm{Hg}$. Because her hypoxic symp- toms were related to the development of pulmonary vascular disease she was considered to be inoperable.

There are two survivors with only a functioning Glenn anastomosis performed at age 14 years (case 21) and two months (case 25). A patient (case 9, age 18) with a functioning Glenn anastomosis and Blalock Taussig shunt is well and does not wish to have further surgery at this time. One patient (case 21) is awaiting a Fontan operation and another (case 25), who attends another hospital, declines investigation.

\section{Mortality}

Four patients aged 17-30 years died; one (case 26) unexpectedly at the age of 30 , eight years after an aortopulmonary Dacron shunt at 22 years. Patient 27 , aged 19 years, with pulmonary atresia was seriously disabled for five years and died of pulmonary hypertension caused by his previous BlalockTaussig shunt and of chronic left ventricular failure from aortic regurgitation. Patient 28 was severely hypoxic with syncope and thrombosed pulmonary arteries and he died aged 18 after a fourth attempt to establish a shunt. A girl (case 29) with two previous shunts died aged 17 years with left ventricular and renal failure caused by glomerulonephritis that required dialysis. She died after cardiac transplantation because the pulmonary artery pressure was raised and the right ventricle of the transplanted heart failed.

\section{Arrhythmias}

Six of the 10 patients have arrhythmias. These caused symptoms in two at ages 26 (case 18) and 30 years (case 17). When atrial fibrillation developed in patient 18, 24 years after a Potts operation, severe right sided congestion and ascites also developed, but she rapidly improved after cardioversion to sinus rhythm. Three years later she had complete heart block that caused syncope and required pacing. Atrial tachycardia in case $\mathbf{1 7}$ is controlled by verapamil.

Asymptomatic arrhythmias were found in four patients. One had non-sustained atrial tachycardia (case 23); another (case 16) had episodes of atrioventricular dissociation, sinus arrest, and junctional rhythm; and the other two patients had ventricular arrhythmias, either frequent ventricular extrasystoles (case 20) or couplets (case 24). Arrhythmias were not more frequent in those with reduced left ventricular ejection fraction.

\section{Functional status of survivors}

The 10 survivors aged 18-35 years (mean 25) have some cyanosis at rest, but ability indices show that seven lead nearly normal lives (table 2). Nine performed the symptom limited exercise test and were 


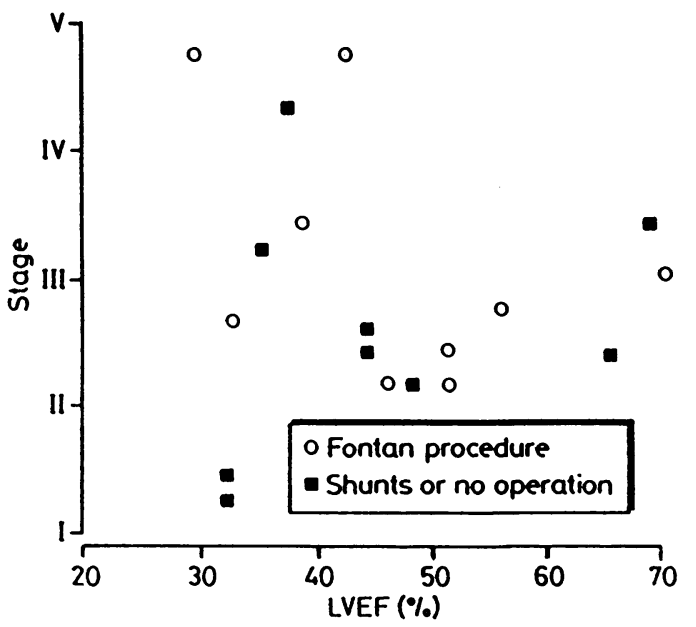

Fig 6 Exercise capacity and left ventricular ejection fraction (LVEF) of nine patients with a Fontan operation and nine patients with palliative shunts or no operation. There is no correlation between these two variables.

stopped by leg fatigue, dyspnoea, or both, with increasing cyanosis. Two patients were limited to stage I. None developed arrhythmias during exercise. Figure 5 shows the exercise capacity and ability index of each patient. There appeared to be no correlation between these two results.

Radionuclide measurement of left ventricular ejection fractions ranged from $32 \%$ to $69 \%$ (mean 46) (table 2). Those with longstanding or multiple shunts did not have worse left ventricular function than the others. In the two patients (cases 21 and 25) with a Glenn anastomosis the measured ejection fraction is $66 \%$ in one and is probably good in the other who refuses investigation. There was no correlation between left ventricular ejection fraction and exercise capacity (fig 6 ) or ability index (fig 7).

\section{Quality of life}

School and employment-Three patients attended schools for the handicapped. Six patients are now working. The other patients feel unable to work, except for patient 23 who has completed a youth training scheme and cannot find employment.

Marriage-Two patients (cases 16 and 18) married. Case 16 has two normal children. The woman (case 18) was sterilised and is now separated from her husband; the marriage broke up because her husband could not cope with her illness.

Driving and life insurance-Five patients have obtained driving licences, one (case 20) has an invalid car and one is a taxi driver. One patient (case 17) has obtained life insurance and another was turned down. No others tried for it.
Medication-Three patients take no medication and the others are on diuretics or antiarrhythmic treatment or both.

Extracardiac problems-Four patients have extracardiac problems. Case 18 has scoliosis. There was a cerebrovascular accident at the time of a further unsuccessful surgical shunt in case 19 and he has a detached retina and bilateral ankle arthropathy. Patient 25 has epilepsy related to a cerebrovascular incident during catheterisation in infancy. Patient 22 is a carrier of hepatitis and has chronic painful arthropathy.

\section{Discussion}

This group of patients has been selected by their achieving maturity. This and their referral from other centres because of problems may explain the high frequency of complications. Thus, these patients may not be truly representative of the incidence of complications in adolescence and adult life. This review, however, does show what can happen in late survivors with tricuspid atresia and normally related great arteries. Because this is the simplest

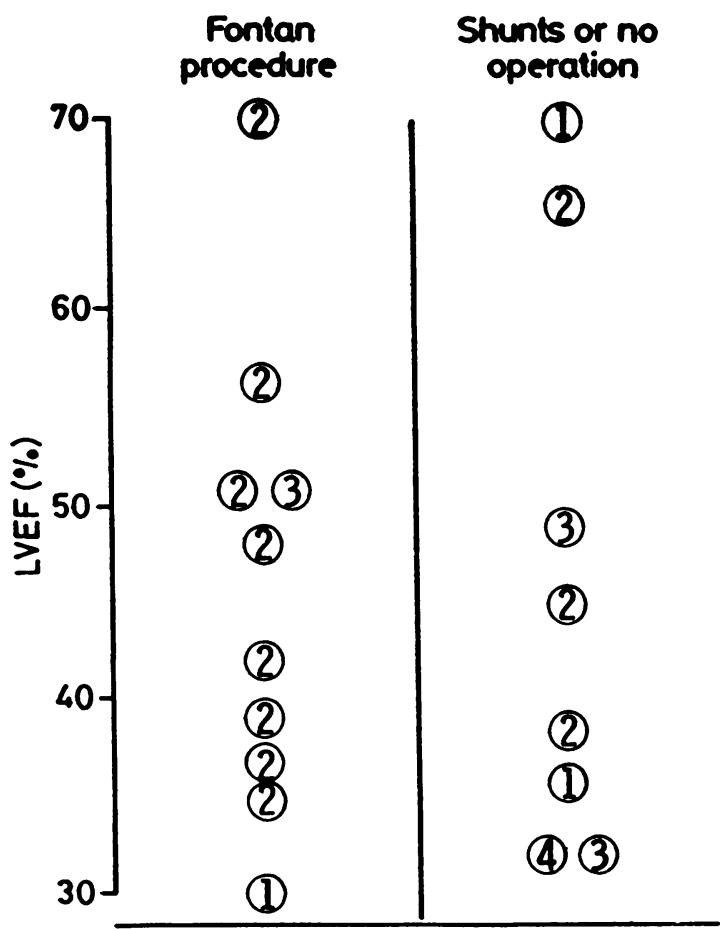

Fig 7 Left ventricular ejection fraction (LVEF) of 10 patients with a Fontan operation and eight with palliative shunts or no operation. The ability index of each patient is shown. 
form of tricuspid atresia, it presumably is the type with the most favourable prognosis. Many patients had palliative procedures during the 1960 s and early 1970s. Much has been learnt since then and techniques have been improved. Some of the complications we saw may not occur in the future.

The status of those who had a Fontan procedure (group 1) is slightly better than those who had palliative procedures (group 2). These marginal differences are reflected in better ability indices, greater exercise capacity, and fewer social and extracardiac problems. There is no difference, however, in left ventricular ejection fraction between the two groups, nor in the incidence of arrhythmias, which are common in both groups and probably age related.

Despite measured limitation of exercise capacity and left ventricular ejection fraction, many patients in both groups lead nearly normal lives as judged by the ability index. In both groups marriage and interpersonal relationships have been more successful for the men than for the women. All the offspring are normal. No women have had children in this series and its seems unlikely that any could have a successful pregnancy at the present time. The need for reoperation in both groups is similar but could have been reduced in the Fontan group by more meticulous surgical technique and the avoidance of Dacron conduits. Mortality in groups 1 and 2 was similar and often occurred when operative procedures were performed on patients with left ventricular dysfunction, pulmonary hypertension, or small pulmonary arteries.

The ability index gives a more useful assessment of the quality of life and the ability to lead it than the New York Heart Association classification, which is the conventional assessment of disability and really measures effort tolerance. The ability index is based on a positive rather than a negative approach and reflects a patient's ability to adapt to his physical problems. Thus it assesses the "distress" caused by illness as well as effort tolerance and these two factors are important when judging the normality and quality of life.

Radionuclide measurement of left ventricular ejection fraction in tricuspid atresia offers a noninvasive method of studying left ventricular function ${ }^{1}$ but there may be difficulty in determining the left ventricular contour in the presence of a ventricular septal defect and a small outlet chamber. Thus we have some doubts about the accuracy of our measurements and do not reject a patient for a Fontan procedure on the basis of a single result by this technique alone. Few patients had left ventricular angiography within a reasonable time of the radionuclide study and so the results cannot be com- pared; but left ventricular ejection fraction was also assessed in each patient by cross sectional echocardiography and these results were similar. Nuclear magnetic resonance studies of left ventricular function are more likely to be accurate and we are assessing their usefulness.

Although volume overload from previous shunts might be expected to impair left ventricular function, the effects are unpredictable and those patients with arteriopulmonary shunts inserted in infancy did not have worse left ventricular function than the others. Similarly, the age at which the Fontan operation was performed did not appear to influence left ventricular function in any way. Thus there is no straightforward relation between left ventricular function and duration of volume overload nor between left ventricular function and the degree of clinical hypoxia. Previous angiographic studies have also failed to find correlations between these variables. ${ }^{23}$ It seems likely that although volume overload is an important cause of left ventricular dysfunction, other factors must exert some influence. Notably, the one patient who did not have surgery (case 18 ) had an ejection fraction of only $32 \%$. Since the left ventricle itself is intrinsically abnormal in this condition, the long term function is unpredictable. Subtle differences from normal left ventricular function have also been reported previously in patients with univentricular-atrioventricular connection and normal ejection fraction. ${ }^{4}$ In addition, some ventricular function appears to be lost at the time of Fontan operation and, perhaps because the ventricle is abnormal, left ventricular function appears to deteriorate with time. Coronarybronchial collaterals may contribute to left ventricular deterioration by causing a steal phenomenon and these vessels were found in three patients in this series; in one they caused angina. This complication may well be a cause of late symptoms in adults with tricuspid or pulmonary atresia who have repeated thoracotomies, particularly mediastinal surgery.

Arrhythmias occurred in $50 \%$ of the survivors, and they were equally common in both groups. All patients except one were older than 20 years at the onset of the arrhythmia; thus it appears to be part of the natural development of the disease. Ambulatory electrocardiographic monitoring may detect arrhythmias in symptom free patients and we believe that it should be performed annually in all patients. The one patient (case 18) in whom complete heart block developed posed a difficult problem in siting the pacemaker wire. To avoid the complications of epicardial and left ventricular pacing, she was paced successfully from the coronary sinus and has remained well for a year.

It is important to decide which form of palliation 
is most likely to lead to survival into adulthood. Most patients (23 of $29(79 \%)$ ) needed operation before the age of 10 , and $14(48 \%)$ required it during infancy. Because different surgeons performed different palliative procedures it is difficult to determine which was the most successful procedure. Similar dangers are inherent in both Potts and Waterston anastomoses because they tend to be too large, to damage a pulmonary artery, to increase pulmonary vascular resistance, or overload the left ventricle. Such anastomoses certainly caused problems in three patients when subsequent Fontan operations were undertaken (cases 11, 12 and 13). In one other patient with a Waterston anastomosis left ventricular failure was so severe that cardiac transplantation was all that could be considered. In some patients, however, these shunts provided satisfactory palliation, and three patients had successful Fontan procedures 4-15 years later. Two patients who had a Potts shunt at six and 18 months (cases 20 and 18) have adequate left ventricular function in sinus rhythm, but one has a stenosed shunt and the other has pulmonary hypertension. Because of problems such as these we do not recommend these shunts for early palliation.

It has been difficult to evaluate the role of the Glenn operation because only two of the 11 patients with a Glenn anastomosis survived with that as the sole palliation. Both retained good left ventricular function, as did the others with Glenn anastomoses, before they had further surgical interventions. A considerable number of patients suffer clinical deterioration within a decade of the Glenn anastomosis being created. This is the result of demands increased by growth and age or a decrease in pulmonary blood flow or both. ${ }^{5}$ In two patients in our series stenosis or occlusion of the anastomosis developed. Other major problems include the development of arteriovenous fistulas in the right lung, which have been demonstrated in three of our patients, caval collaterals, and fistulisation of the superior vena cava-right atrial junction, ${ }^{6}$ which occurred in two. Thus there may be long term problems with a Glenn anastomosis but the anastomosis is good for the long term function of the left ventricle, which is critical in this disease.

The best initial palliation appears to be the Blalock-Taussig shunt ${ }^{78}$ modified with Goretex interposition and carried out with impeccable technique to prevent distortion of the pulmonary arteries. The size of the shunt must be controlled so that the left ventricle is not overloaded. Eighteen $(62 \%)$ of the 29 patients in this series had a BlalockTaussig shunt performed. In one patient (case 27) with pulmonary atresia a Blalock-Taussig shunt caused pulmonary hypertension and he died sud- denly. The others with this shunt have no serious long term complications. Two patients who survive with Blalock-Taussig shunts (cases 22 and 23) have measured impairment of left ventricular function but lead normal lives.

Whatever type of palliation is chosen, early postoperative investigation in the first year is mandatory to ensure that the pulmonary arteries are not distorted, that both pulmonary arteries are perfused, and that the shunt is not so large that it is predisposing the patient to premature left ventricular dysfunction or pulmonary vascular disease. So often these features are found too late when the patient is referred for further surgery after clinical deterioration. These patients must have careful regular non-invasive measurement of left ventricular function and of cardiac size, and determined efforts must be made to measure pulmonary artery pressure and calculate pulmonary vascular resistance. We recognise that calculation of pulmonary vascular resistance may be inaccurate because of the assumptions inherent in the method.

Natural long term survival, although infrequent, is possible in patients with tricuspid atresia and normally related great arteries, and survival to 51 years without surgery has been reported. ${ }^{9}$ Such survival requires a ventricular septal defect that is not so large in infancy that it causes irreversible failure or pulmonary hypertension and yet not so small as to cause profound hypoxia. The association of pulmonary valve stenosis with a large ventricular septal defect may also permit long term survival. When this occurs the right ventricular outflow tract is of good size, as are the pulmonary arteries, and such patients should be suitable for Fontan procedures or a modification. This was the case in only two of our four patients who reached 20 years without palliation (cases 1 and 26), but patient 26 had a palliative procedure before the Fontan procedure was devised. ${ }^{10}$ Two were not suitable for a Fontan procedure: one because of small pulmonary arteries (case 19) and the other because of pulmonary vascular disease (case 17).

The best management for patients with symptomatic tricuspid atresia in adolescence and adulthood has yet to be determined. The Fontan operation has a place in the management of older patients $(\geqslant 14$ years) but mortality is high $-50 \%$ in this series. The high mortality is related to errors in selection. Results in survivors are good and are maintained provided that Dacron conduits are not used and that strict selection criteria are adhered to. Impeccable surgery is mandatory. Eight older patients had shunts which relieved hypoxic symptoms, provided that a Dacron interposition was not used and that the pulmonary arteries were not already throm- 
bosed. A Waterston or Potts shunt at this age tended to produce progressive deterioration in left ventricular function, precluding a successful Fontan procedure. We feel the Fontan procedure is the better option if the ideal criteria are fulfilled. If not, then a Blalock-Taussig shunt is, once again, the shunt of choice. If left ventricular function is too poor cardiac transplantation is the only option. Those with palliative shunts will probably require both heart and lung transplantation because of pulmonary vascular disease and there will be difficulties with bleeding at the site of the previous thoracotomy. Whether patients in whom a Fontan procedure has been performed in childhood will do as well as those with palliative shunts remains to be determined.

Carole Warnes is supported by the British Heart Foundation.

\section{References}

1 Baker EJ, Jones ODH, Joseph MC, Maisey MN, Tynan MJ. Radionuclide measurement of left ventricular ejection fraction in tricuspid atresia. Br Heart f 1984;52:572-4.
2 Sauer U, Mocellin R. Angiographic left volume determination in tricuspid atresia. Comparison of patients with and without palliative surgery. Herz 1979;4: 248-55.

3 Graham TP Jr, Erath HG Jr, Boucek RJ Jr, et al. Left ventricular function in cyanotic congenital heart disease. Am $\mathcal{F}$ Cardiol 1980;45:1231-6.

4 Gibson DG, Traill TA, Brown DJ. Abnormal ventricular function in patients with univentricular heart. Herz 1979;4:226-31.

5 Bargeron LM, Karp RB, Barcia A, Kirklin JW, Hunt $D$, Deverall PB. Late deterioration of patients after superior vena cava to right pulmonary artery anastomosis. Am $\mathcal{F}$ Cardiol 1972;30:211-6.

6 Mathur M, Glenn WWL. Long term evaluation of cava-pulmonary artery anastomosis. Surgery 1973; 74:899-916.

7 Trusler GA, Williams WG. Long-term results of shunt procedures for tricuspid atresia. Ann Thorac Surg 1980;29:312-6.

8 De Brux JL, Zannini L, Binet JP, et al. Tricuspid atresia. Results of treatment in 115 children. f Thorac Cardiovasc Surg 1983;85:440-6.

9 Cooke FN, Hernandez FA. Tricuspid atresia: a case report of a 51 year old woman treated by. an extracardiac shunt. South Med F 1959;52:1016-8.

10 Fontan F, Baudet E. Surgical repair of tricuspid atresia. Thorax 1971;26:240-8. 